\title{
Single Point Outer Race Bearing Fault Severity Estimation using Stator Current Measurements
}

\author{
Bram Corne $^{1}$, Bram Vervisch ${ }^{1}$, Stijn Derammelaere ${ }^{1}$, Sérgio M. A. Cruz $^{2}$, Jos Knockaert ${ }^{1}$, Jan Desmet ${ }^{1}$ \\ ${ }^{1}$ EELAB - EEMMeCS, Ghent University, Graaf Karel de Goedelaan 5, B-8500 Kortrijk, Belgium \\ ${ }^{2}$ University of Coimbra and Instituto de Telecomunicações, Department of Electrical and Computer Engineering, \\ Pólo II - Pinhal de Marrocos, P - 3030-290 Coimbra, Portugal
}

\begin{abstract}
Although numerous valuable research has been conducted by many authors, the relation between evolving mechanical faults and their fault-indicating reflections in the electrical signals of rotating electric machinery still requires extensive attention. This lack of information implies serious obstructions in the evolution of applying motor current signature analysis as a complete and reliable condition monitoring technology. However, as previous research of the authors resulted in the construction of a unique test-bench where specific mechanical faults can be introduced into an $11 \mathrm{~kW}$ induction machine with high reproducibility and accuracy, the relations between evolving mechanical faults and their reflections in the stator current can be investigated and quantified experimentally. Using this mechanical fault-emulator, experiments where conducted where the severity of a single point outer race bearing fault and its corresponding signature in the stator current's spectral fault-components are accurately analyzed. These evolving faulty components are trended and characterized, resulting in the desired quantification of the mechanical fault-severity. Based on these results, it is possible to inversely estimate the severity of single point outer race bearing problems by acquiring nothing more then the stator current timefunctions.
\end{abstract}

Index Terms-Condition monitoring, Fault diagnosis, Induction motors, Emulation, Ball bearings

\section{INTRODUCTION}

Validation is an implicit part of developing a condition monitoring technology. Reasonably, as the increase of the machine's reliability can only be a consequence of implementing reliable technologies. Due to the need of validation on an academic level (technical proof-of-concept), many authors have been searching extensively on methodologies which can implement quantified bearing-related faults in electric rotating machinery with focus on both reproducibility and industrial relevance, [1]-[10]. The widely accepted and applied method is replacing one of the bearings of the machine under test by a bearing suffering from an artificially implemented fault (e.g. emulating single point bearing pitting by drilling holes through the outer race, [3]-[10]). That method satisfies the need of proving the feasibility of some technologies, but is inadequate to perform detailed, reproducible research on e.g. estimating the severity of evolving condition monitoring technologies. This is mainly because, unfortunately, the reproducibility is lost by remounting the bearing, as system characteristics such as stiffness and damping highly depend on the mounting of the bearing and have a severe impact on the machine's faulty behavior. It should be noted that this obstruction is of less value when vibration-based condition monitoring is tested. Comprehensibly, as accelerometers measure the interacting forces (proportional to acceleration) between the stator and the rotor, while current analysis highly depends on the displacement between the stator and the rotor. This implication confirms the importance of the system's characteristics. Nevertheless, the way artificial faults are generally machined onto the bearing is often not equivalent to realistic, industrial conditions. Consequently, the relevance of the obtained results decreases impermissible.

The core research of the authors concerns the detection of mechanical faults in electric rotating machinery by analyzing the machine's electrical signals. A few decades ago, research sufficiently proved the feasibility of using the stator current to examine both the electrical and mechanical conditions of the electric machine, [1]-[3], [11]. Unfortunately, until today, the determination of severity-stages when specific mechanical faults are evolving is still lacking, [12]. Due to the absence of the urgency-statement when a mechanical problem is detected, the technology is unfortunately categorized as unserviceable. Comprehensively, because the machine's operator is deficiently informed with an alarming message such as "There is a problem with the drive-end bearing of machine X.". The operator needs a time-based severity estimation in order to be able to plan the reparation and/or replacement, fully depending on the urgency of the problem. This shortcoming can only be nullified if the relation between mechanical faultseverity and their reflection in the electrical signals e.g. the stator current can be investigated thoroughly. Driven by this problem-statement, the authors created a novel method in order to emulate mechanical faults with high reproducibility and accuracy, [13]. Consequently, investigating the relations between mechanical fault-severity and the stator current fault signatures under different environmental influences becomes possible. The fundamental principle of the fault-emulator is the replacement of the drive-end side mechanical bearing of an $11 \mathrm{~kW}$ Induction Machine (IM) with an Active Magnetic Bearing (AMB). Thereby, the radial position of the rotor can be manipulated at every moment in time with respect to the stator's position. Because an occurring mechanical fault can commonly be characterized as a specific radial movement between the machine's rotor and stator, mechanical faults can be emulated by accurately controlling the set-points for the magnetic bearing. As a result, specific rotor-movements related to quantified mechanical faults can be imposed onto the machine with a wide variety of controllable environmental 
conditions. All this while the IM's electrical signals are carefully analyzed. The most vital and challenging part in this approach is characterizing the movements between the rotor and stator during evolving faulty conditions. Those movements are analytically obtained and validated in [13] for single point bearing faults and are further analyzed and applied in this paper.

The specification of the rotor-movements when a single point outer race bearing pit is developing is handled in §II. This with the focus on the dependency of the fault's dimensions, severity and other parameters on those movements. The obtained movements will serve as set-points for the AMB, of which the principle, dimensioning and implementation is briefly discussed in §III. Specific scientific details regarding $\S$ II and §III can be found in [13]. After completely constructing and implementing the whole AMB-system, extensive experiments are conducted. The relation between an evolving single point outer race bearing fault and the stator current's signature is measured, spectrally analyzed and discussed in $\S I V$. Conclusions regarding this paper and a view on future research can be found in $\S \mathrm{V}$.

\section{BEARING FAULT ROTOR-MOVEMENTS}

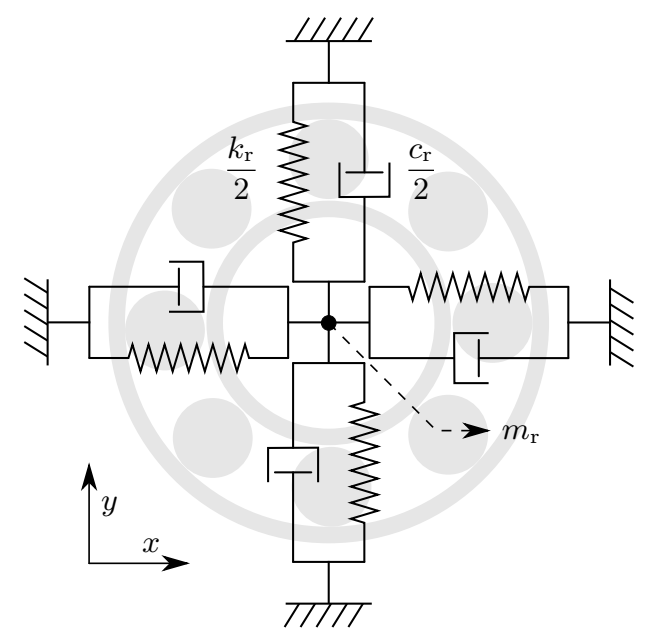

Figure 1: The relation between the stator and the rotor is represented by a $2 \mathrm{DOF}$ model

The fundamental idea of the mechanical fault-emulating test-rig is inducing a well-known movement of the rotor with respect to the stator. In this paper, that specific movement has to correspond to a quantified bearing fault. Consequently, information must be acquired about the radial rotor-movements for all kinds of single point outer race bearing faults regarding severity conditions, rotor speed, bearing fault location, bearing parameters, bearing properties... It would be advantageous if those movements can fully be obtained by an analytical approach, so different rotor-movements under changing conditions can be rapidly calculated by a real-time controller and sequentially induced in the fault-emulator. In order to do so, the machine's ball bearing is defined as a Two Degree Of Freedom (2DOF) mass-spring-damper system with both a horizontal and vertical freedom of motion (Figure 1), [14]. The system is completely described by a mass $m_{\mathrm{r}}$, a radial stiffness $k_{\mathrm{r}}$ and a radial damping $c_{\mathrm{r}}$, combined in the set of force-equations:

$$
\left\{\begin{array}{l}
f_{\mathrm{y}}(t)=m_{\mathrm{r}} \cdot \ddot{y}(t)+c_{\mathrm{r}} \cdot \dot{y}(t)+k_{\mathrm{r}} \cdot y(t) \\
f_{\mathrm{x}}(t)=m_{\mathrm{r}} \cdot \ddot{x}(t)+c_{\mathrm{r}} \cdot \dot{x}(t)+k_{\mathrm{r}} \cdot x(t)
\end{array}\right.
$$

The mass $m_{\mathrm{r}}$ is the equivalent mass of the rotor supported by the bearing. $y(t)$ and $x(t)$ represent respectively the vertical and horizontal position at time $t . f_{\mathrm{y}}(t)$ and $f_{\mathrm{x}}(t)$ are representing the acting forces between the rotor and the stator. $\ddot{y}(t), \ddot{x}(t)$ and $\dot{y}(t), \dot{x}(t)$ are respectively the acceleration and velocity of the rotor with respect to the stator in the vertical and horizontal direction. The time-based force-functions, $f_{\mathrm{y}}(t)$ and $f_{\mathrm{x}}(t)$, can be constructed in such a way that they fully represent the faulty bearing's behavior. This is theoretically possible because the bearing fault actually imposes specific interacting forces between the stator and rotor. By exciting the 2DOF-system with the obtained fault-related force-functions using mathematical algorithms [15], the resulting system responses, $x(t)$, will completely determine the rotor-movement for each specific faulty condition. The following subsection will briefly handle the construction of those force-functions for single point outer race bearing faults. Using these advanced algorithms, rotormovements for a wide range of faulty bearing-conditions can be obtained with high accuracy.

\section{A. Outer race bearing fault}

In order to obtain the interacting force-functions between the rotor and the stator $f_{\mathrm{y}}(t)$ and $f_{\mathrm{x}}(t)$ for a specific case, the faulty condition must be characterized precisely. Regarding the characterization of single point outer race bearing faults, a single point pit is plotted in Figure 2. The pit is defined by the length $l_{\text {pit }}$, depth $d_{\text {pit }}$ and angle $\gamma_{\text {pit }}$. The angle $\alpha_{\text {pit }}$ is the angular position of the pit on the bearing's outer race with respect to the vertical centerline through the bearing's center point. By the quantification of this pit, calculations can be made regarding the interacting forces when a bearing ball (and so the unsupported rotor) falls into the pit and is subsequently restored in its original circular track.

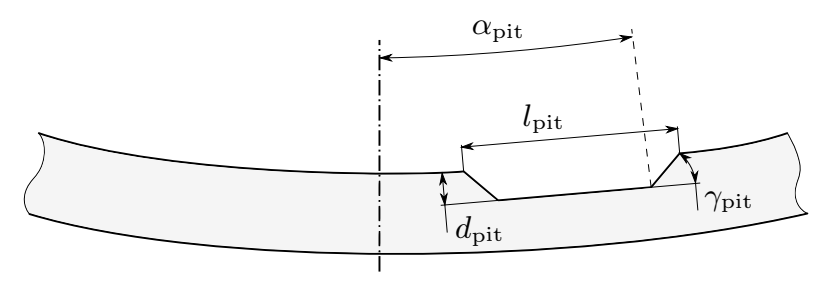

Figure 2: A characterized single point bearing pit

During rotation, the presence of the pit in the outer race has an unique periodic impact on the rotor's position. This periodicity, $t_{\mathrm{o}}$, is related to the speed by which the bearing balls are passing the pit. This period determines the fundamental period of the faulty force-functions and is as well the frequency that can be found in the stator current's spectrum (modulated on the fundamental current component, [2]-[4], [10]). As the outer race pit can be located at every angular position (defined by $\alpha_{\text {pit }}$ ), the 2DOF-system gets always excited in the two directions $x$ and $y$ (except for $\alpha_{\text {pit }}=-\frac{\pi}{2} ; 0 ; \frac{\pi}{2} ; \pi$ ). 
Therefore, the faulty force-function is subdivided in a vertical and horizontal force-component, respectively $f_{\mathrm{y}}(t)$ and $f_{\mathrm{x}}(t)$. For illustration, the vertical force-function acting on the 2DOF-system is shaped and parameterized in Figure 3. The magnitudes of the fault-related force-function is defined by a negative force $I_{\mathrm{n}, \mathrm{y}}$ (when the rotor is in free fall) and a positive force $I_{\mathrm{p}, \mathrm{y}}$ (when the rotor is pushed back to the center). These forces have a corresponding duration of acting defined by $t_{\mathrm{n}}$ and $t_{\mathrm{p}}$. All these mentioned parameters are defined for $\alpha_{\text {pit }} \in\left[-\frac{\pi}{2} ; \frac{\pi}{2}\right]$ as follows, [13]:

$$
\begin{aligned}
I_{\mathrm{p}, \mathrm{y}} & =m_{\mathrm{r}} \cdot g\left(\frac{t_{\mathrm{n}}^{2}}{2 \cdot t_{\mathrm{p}}^{2}} \cos ^{2}\left(\alpha_{\mathrm{pit}}\right)-1\right) \\
I_{\mathrm{n}, \mathrm{y}} & =-m_{\mathrm{r}} \cdot g \\
t_{\mathrm{o}} & =\frac{1}{n_{\mathrm{b}} \cdot f_{\mathrm{FTF}}} \\
t_{\mathrm{p}} & =\frac{g \cdot t_{\mathrm{n}}^{2}}{2 \pi \cdot p d \cdot f_{\mathrm{FTF}} \cdot \tan \left(\gamma_{\mathrm{pit}}\right)} \cdot \cos \left(\alpha_{\mathrm{pit}}\right) \\
t_{\mathrm{n}} & =\frac{l_{\mathrm{pit}}}{\pi \cdot p d \cdot f_{\mathrm{FTF}}}
\end{aligned}
$$

with:

$$
f_{\mathrm{FTF}}=\frac{f_{\mathrm{r}}}{2}\left(1-\frac{b d}{p d} \cos \beta\right)
$$

and with: $g$, the gravitational acceleration; $n_{\mathrm{b}}$, the number of bearing balls; $f_{\mathrm{r}}$, the rotational speed; $p d$, the pitch diameter; $b d$, the bearing ball diameter and $\beta$, the bearing contact angle.

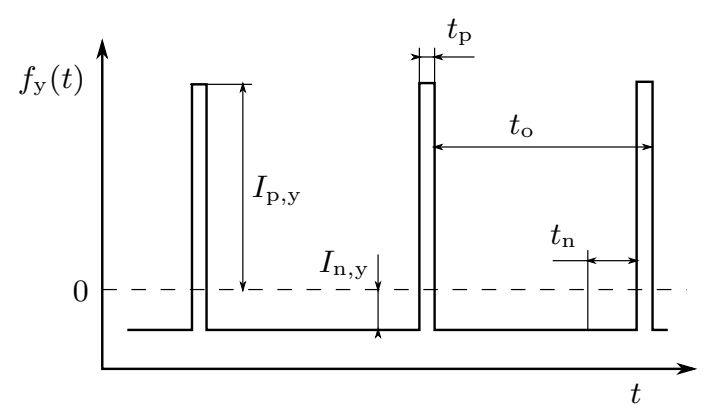

Figure 3: Parameterized vertical outer race force-function

Regarding the horizontal force-function $f_{\mathrm{x}}(t)$, the times $t_{\mathrm{O}}$, $t_{\mathrm{p}}$ and $t_{\mathrm{n}}$ remain exactly the same. Due to the change of direction of the gravitational force, the magnitudes $I_{\mathrm{p}, \mathrm{x}}$ and $I_{\mathrm{n}, \mathrm{x}}$ can now be written as, [13]:

$$
\begin{aligned}
& I_{\mathrm{p}, \mathrm{x}}=m_{\mathrm{r}} \cdot g \frac{t_{\mathrm{n}}^{2}}{4 \cdot t_{\mathrm{p}}^{2}} \sin \left(2 \cdot \alpha_{\mathrm{pit}}\right) \\
& I_{\mathrm{n}, \mathrm{x}}=0
\end{aligned}
$$

When a single point bearing fault is evolving in terms of severity, the main varying parameter is the pit-length $l_{\text {pit }}$ as detailed later on in the paper. In order to analyze the effect of severity on the force-functions, Figure 4 is obtained which visualizes the relation between the positive force-magnitude $I_{\mathrm{p}, \mathrm{y}}$ and the pit-length $l_{\text {pit }}$. It can be concluded that the relation between the main fault-related force and the severity of the fault is defined by a quadratic function. However, that doesn't
Table I: Calculation parameters

\begin{tabular}{c|c|c} 
Parameter & Value & Unit \\
\hline \hline$l_{\text {pit }}$ & 2 & {$[\mathrm{~mm}]$} \\
\hline$d_{\text {pit }}$ & 200 & {$[\mu \mathrm{m}]$} \\
\hline$\gamma_{\text {pit }}$ & $\frac{\pi}{6}$ & {$[\mathrm{rad}]$} \\
\hline$\alpha_{\text {pit }}$ & 0 & {$[\mathrm{rad}]$} \\
\hline$p d$ & 17.5 & {$[\mathrm{~mm}]$} \\
\hline$b d$ & 7.4 & {$[\mathrm{~mm}]$} \\
\hline$\beta$ & 0 & {$[\mathrm{rad}]$} \\
\hline$n_{\mathrm{b}}$ & 8 & {$[-]$} \\
\hline$f_{\mathrm{r}}$ & 24.8 & {$[\mathrm{~Hz}]$} \\
\hline$m_{\mathrm{r}}$ & 21.9 & {$[\mathrm{~kg}]$} \\
\hline$c_{\mathrm{r}}$ & 14.53 & {$[\mathrm{kNs} / \mathrm{m}]$} \\
\hline$k_{\mathrm{r}}$ & $2.85 \cdot 10^{5}$ & {$[\mathrm{kN} / \mathrm{mm}]$} \\
\hline$g$ & 9.81 & {$\left[\mathrm{~m} / \mathrm{s}^{2}\right]$} \\
\hline
\end{tabular}

imply that the relation between fault-severity and the signatures reflected in the stator current will be quadratic, because the rotor-displacement is equally depending on the time $t_{\mathrm{p}}$ as it is on the force $I_{\mathrm{p}, \mathrm{y}}$. Using the mathematical software-tool described in [15], the 2DOF-system is analytically excited by the force-functions obtained for a specific case of which the parameters are listed in Table I. The corresponding vertical response-function, in position $x(t)$, is presented in Figure 5. With the use of this method, the rotor-movement of each specified single point outer race bearing fault can be obtained for a wide variety of influential conditions regarding rotor-speed, pit-dimensions, bearing-parameters, bearing-characteristics...

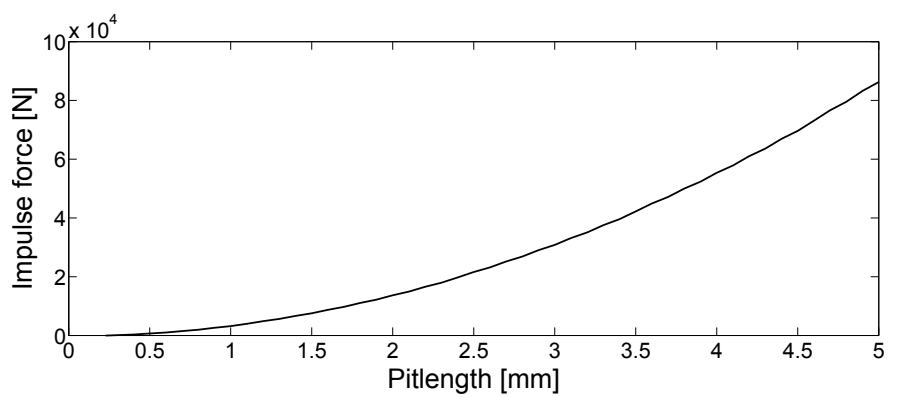

Figure 4: Impulse magnitude of a single point outer race pit as a function of the pit-length, $l_{\text {pit }}$ (parameters specified in Table I)

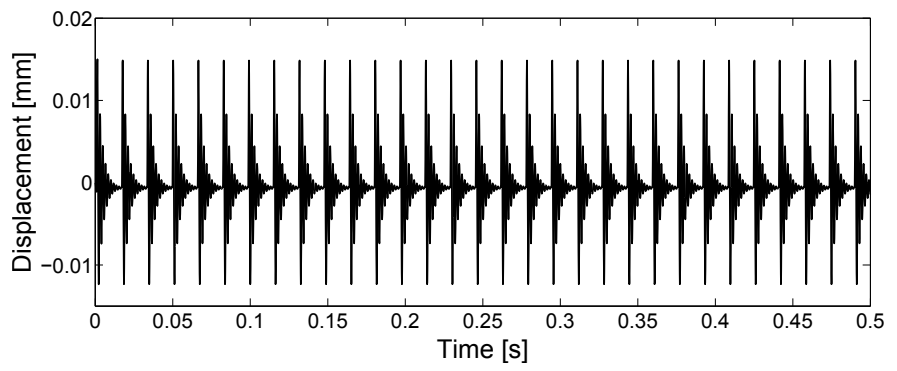

Figure 5: Vertical rotor-displacement for a single point bearing outer race fault (parameters specified in Table I) 
In order to visualize the effect of an evolving single point pit on the absolute movements of the rotor with respect to the stator, Figure 6 is constructed by simulations. In that figure, the maximum displacement of the rotor with respect to the stator is presented as a function of both the pit-depth and pit-length. The analysis clearly elucidates the influence and impact of both the depth and length of the pit on the rotormovements. The depth of the pit plays an important role when the pit is sufficiently long. This because for long pits, the falling bearing ball collides with the bottom of the pit. From that point on, when the pit-length further increases, it does not influence the movement of the rotor in magnitude anymore. Logically, because the force needed to restore the bearing ball in the circular track remains equal. Additionally, the pit-depth does not have any influence on the movements for short pits, because the bearing ball does not have time to reach the bottom surface of the single point bearing pit. As the severity of single point outer race bearing-faults is largely characterized by the length of the pit, emulations are made with the pit-length as main varying parameter. To exclude a strong influence of the pit-depth on the measurements, a realistic depth of $200 \mu \mathrm{m}$ is chosen for the experiments conducted in §IV.

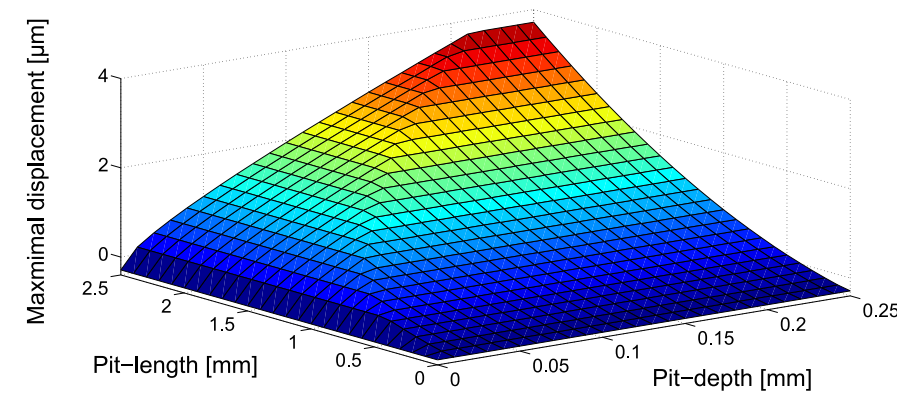

Figure 6: Maximum rotor-displacement for a single point bearing outer race fault under varying pit-depth and pit-length.

\section{Magnetic BeARING AS A ROTOR EXCITER}

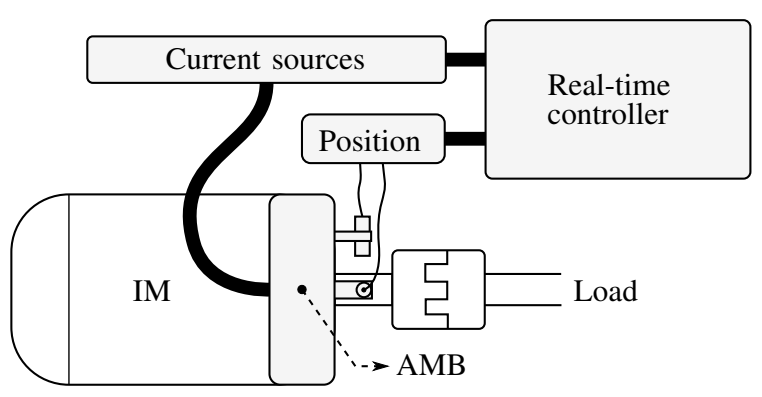

Figure 7: Concept of an AMB as a mechanical fault emulator

The rotor/stator-movements are analytically defined for numerous single point inner and outer race bearing faults. That knowledge creates the opportunity of emulating those bearing faults in an electric machine. This goal can only be achieved when those specific rotor-movements are imposed on a machine with high precision and reproducibility. As mentioned in $\S \mathrm{I}$ and conceptually presented in Figure 7, an IM's drive-end bearing is replaced by an AMB in order to introduce the faultrelated rotor-movements. Consequently, the rotor's position can be manipulated at every moment in time according to the response-functions obtained in §II-A. However, the magnetic bearing must be able to take over the key functionalities of the original mechanical bearing. This consists of counter-forcing gravity, mechanical (mass) unbalance, unbalanced magnetic pull and any other imposed external forces. All these forces in combination with the desired rotor-movements determine the power-range and so the physical dimensions of the bearing, expressed in [13], [16], [17]:

$$
F(t)=\mu_{0}\left(\frac{N \cdot i(t)}{\frac{l_{\text {stat }}}{\mu_{\mathrm{r}_{\text {stat }}}}+\frac{l_{\mathrm{sh}}}{\mu_{\mathrm{r}_{\mathrm{sh}}}}+2 \cdot z(t)}\right)^{2} A_{\mathrm{a}} \cdot \cos \alpha
$$

with: $F$, the resulting force; $\mu_{0}$, the permeability of vacuum; $N$, the number of turns in the coil; $i$, the current through the coil; $l_{\text {stat }}$, the length of the flux path through the AMB; $l_{\mathrm{sh}}$, the length of the flux path through the rotor-shaft; $\mu_{\mathrm{r}_{\text {stat }}}$, the relative permeability of the AMB's laminated electrical steel; $\mu_{\mathrm{r}_{\mathrm{sh}}}$, the relative permeability of the rotor-shaft; $z$, the mean air-gap between the two AMB-poles and the rotor-shaft; $A_{\mathrm{a}}$, the cross section surface of one pole and $\alpha$, the angle between the generated force and one pole.

Fortunately, lots of research has been done on dimensioning magnetic bearings, their control and their dynamic behavior which could easily be translated into this project, [16]-[20]. In order to obtain a realistic fault-emulator, it is of paramount importance that the magnetic bearing behaves exactly the same as the original mechanical bearing would behave. The interacting forces between the rotor and the stator must be equal for both systems. Therefore, the stiffness and damping characteristics of the mechanical bearing (available from the bearing supplier) are implemented in the control-loop of the magnetic bearing. That control-loop controls four H-bridge current sources (one for every direction: up, down, left and right) based on two-axis radial position measurements. By applying current sources with a sufficiently high DC busvoltage of $175 \mathrm{~V}$, fast varying currents can be induced in the bearing's coils. As a result, high dynamic forces can instantaneously be generated in the bearing. This is essential, as the established forces must be dynamic enough to impose, next to the counter-forces, the obtained rotor-movements.

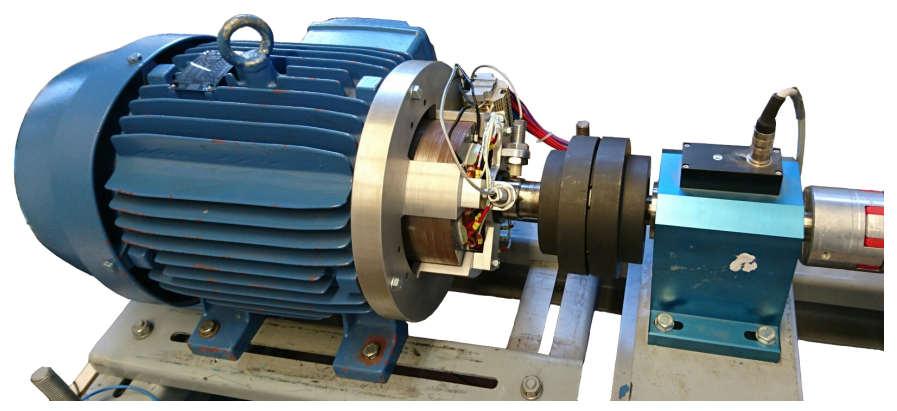

Figure 8: The AMB implemented at drive-end-side of the IM

Since extensive simulations and fine-tuning of the electrical/mechanical system confirmed the technical proof-ofconcept with specific properties and conditions, the magnetic 
bearing was built and implemented in the $11 \mathrm{~kW}$ IM, presented in Figure 8. An aluminum frame was designed in order to align the center of the magnetic bearing with the exact center of the stator of the IM (gray part in Figure 8). Onto that frame, eddy-current probes are fitted which measure the position of the shaft on an inner race of a plain bearing (to obtain a nearly perfect circular surface). A high-end real-time controller (cyclic time of $0.1 \mathrm{~ms}$ ) is implemented in order to execute the control-loop and so control the position of the rotor with high precision. In order to prevent overheating of the magnetic bearing, thermocouples are mounted in all four bearing-coils. Those temperatures are systematically evaluated by the realtime controller, activating an alarming-system as soon as the temperature exceeds the predefined limit $\left(150^{\circ} \mathrm{C}\right)$. An easy accessible user-interface is programmed in order to continuously change and monitor the operational parameters of the IM and the emulation-properties. Three main fault-categories can be emulated: misalignment, rotor mass unbalance and bearing faults. Regarding bearing faults, inner race, outer race and cage bearing faults can be imposed into the IM. Due to being able of changing the fault-properties during operation, the impact of evolving mechanical faults in the stator current can be continuously logged while keeping all environmental influences in a steady-state. In this paper, only experiments of a varying single point bearing outer race pitting are presented.

\section{EXPERIMENTS}

Conclusively, the goal of the test-rig and its experiments is finding the relation between the severity of mechanical faults and their signatures in the stator current's spectrum. If those relations can be quantified, the severity of mechanical faults can be estimated by measuring the stator current. In this experiment, information is obtained regarding the relation between the severity of a single point outer race bearing fault component and its reflection in the stator current spectrum for an $11 \mathrm{~kW}$ IM. The test is initiated by operating the IM at nominal speed without any fault-emulation. At that moment, the AMB is functioning as a regular, mechanical bearing. From thereon, accessing the fault-emulating userinterface, the pit-length of the single point bearing fault is discretely increased while the stator current's time-data is acquired continuously. The time-domain is transformed to the frequency-domain based on the discrete Fourier transform with increased accuracy in magnitude and frequency, of which the algorithm is discussed in [10], based on [15]. The analysis of the frequency-data is executed by an automatic algorithm which searches for time-varying spectral components. In other words, the algorithm searches automatically for the frequencycomponents that have a certain dependency on the pit-length. The result of this analysis is plotted in Figure 9. That figure only presents the frequency-components which have a certain linear/quadratic correlation (coefficient of determination: $\left.r^{2} \geq 0.75\right)$ and a significant positive trend with respect to the pit-length $l_{\text {pit }}$. All other, irrelevant spectral components in the currents' spectra are excluded from Figure 9.

Via Motor Current Signature Analysis (MCSA), stator current frequency-components are related with specific electrical and mechanical problems in the IM (e.g. misalignment, stator winding shortcuts, broken rotor bars, unbalance, bearing outer race problem, bearing cage problem...). These specific faultindicators and their unique signatures in terms of frequency are extensively discussed in [10] and can be summarized for outer race, inner race, ball and bearing cage faults, respectively as [4], [8]-[10], [12], [21]-[26]:

$$
\begin{aligned}
f_{\text {outer }} & =f_{1} \pm k \cdot \frac{n_{\mathrm{b}}}{2} f_{\mathrm{r}}\left[1-\frac{b d}{p d} \cos \beta\right] \\
f_{\text {inner }} & =f_{1} \pm k \cdot \frac{n_{\mathrm{b}}}{2} f_{\mathrm{r}}\left[1+\frac{b d}{p d} \cos \beta\right] \\
f_{\text {ball }} & =f_{1} \pm k \cdot \frac{p d}{2 \cdot b d} f_{\mathrm{r}}\left[1-\left(\frac{b d}{p d} \cos \beta\right)^{2}\right] \\
f_{\text {cage }} & =f_{1} \pm k \cdot \frac{1}{2} f_{\mathrm{r}}\left[1-\frac{b d}{p d} \cos \beta\right]
\end{aligned}
$$

with: $f_{1}$, the fundamental current frequency and the integer $k=1,2,3 \ldots$. The predefined MCSA fault-components can now be matched with the results out of the current analysis presented in Figure 9. Exceedingly, each trending frequencycomponent can in fact be related with bearing problems. The specific link of the valuable current-components and the type of bearing fault is listed in Table II (column Indication). In the other columns, specific information can be found regarding the trending of the component as function of the pit-length. It can be noted that the fault-components are clearly dependent on the pit-length by a quadratic function. If only the outer race bearing fault components are considered, a mean coefficient of determination $\left(r^{2}\right)$ of 0.8997 is obtained. Although only a single point outer race bearing fault is implied on the machine, clear signatures of a bearing ball defect and an inner race bearing fault are as well present in the spectrum. It is common, when a severe bearing fault occurs, all types of bearing fault signatures are propagated. However, the presence of the outer race bearing fault signature is in this case sufficiently differentiated in presence with respect to the others (see harmonic orders $k$ ). Further experiments and analysis will have to be performed on single point inner race bearing faults in order to completely differentiate between both signatures. Anyhow, the estimation of the fault-severity is far more important then the detailed characterization and identification of the fault. As the relation between the fault-severity has a distinct, quantified correlation with the stator-current components, the experiment is considered a success. It can be concluded that the first-order fault-components increase $3 \mathrm{~mA} / \mathrm{mm}$ for this specific $11 \mathrm{~kW}$ IM. As the fault development and the electrical/mechanical relation should be the same for other power-sizes of IMs, the results should easily be extrapolated by validating several measurement-points of the quadratic curve. This statement will have to be confirmed in future research.

\section{CONCLUSION}

Using an analytical method, specific rotor-movements in an IM severing faulty bearing conditions can be calculated for an infinite number of cases and conditions. As the ability is created of inducing those movements in an $11 \mathrm{~kW}$ IM via an 
Table II: Trending functions of the fault-components

\begin{tabular}{c|c|c|c|c|c|c|c|c|c} 
& & & & \multicolumn{3}{|c|}{$f\left(l_{\text {pit }}\right)=a \cdot l_{\text {pit }}+b$} & \multicolumn{3}{|c}{$f\left(l_{\text {pit }}\right)=c \cdot l_{\text {pit }}^{2}+d \cdot l_{\text {pit }}+e$} \\
Frequency $[\mathrm{Hz}]$ & Indication & Order, $k$ & $a$ & $b$ & $r^{2}$ & $c$ & $d$ & $e$ & $r^{2}$ \\
& & & $\mathrm{x} \mathrm{e}-05$ & $\mathrm{x} \mathrm{e}-05$ & & $\mathrm{x} \mathrm{e}-07$ & $\mathrm{x} \mathrm{e}-05$ & $\mathrm{x} \mathrm{e}-05$ & \\
\hline \hline 24.79 & Outer race & -1 & 1.4731 & -13.2909 & 0.7105 & 6.7053 & -1.9466 & 16.3465 & 0.9555 \\
\hline 70.40 & Inner race & -1 & 1.4011 & -13.3183 & 0.7007 & 6.4855 & -1.9066 & 15.3327 & 0.9506 \\
\hline 98.37 & Outer race & -2 & 0.3313 & -1.1442 & 0.4375 & 2.1751 & -0.7779 & 8.4696 & 0.7511 \\
\hline 122.45 & Outer race & 1 & 0.6261 & -6.2064 & 0.7941 & 2.2491 & -0.5209 & 3.7346 & 0.9646 \\
\hline 145.07 & Ball spin & 2 & 0.2547 & -1.4616 & 0.5967 & 1.1216 & -0.3173 & 3.4959 & 0.7893 \\
\hline 171.93 & Outer race & -3 & 0.3381 & -3.2358 & 0.7291 & 1.4842 & -0.4188 & 3.3246 & 0.9628 \\
\hline 196.08 & Outer race & 2 & 0.1195 & -0.6732 & 0.5539 & 0.6541 & -0.2141 & 2.2178 & 0.8299 \\
\hline 269.71 & Outer race & 3 & 0.1423 & -1.5669 & 0.6993 & 0.6489 & -0.1885 & 1.3012 & 0.9410 \\
\hline 287.12 & Inner race & 2 & 0.0891 & -0.5610 & 0.6285 & 0.3740 & -0.1016 & 1.0921 & 0.8127 \\
\hline 416.97 & Outer race & 5 & 0.0336 & -0.1249 & 0.6031 & 0.1512 & -0.0435 & 0.5436 & 0.8065 \\
\hline
\end{tabular}

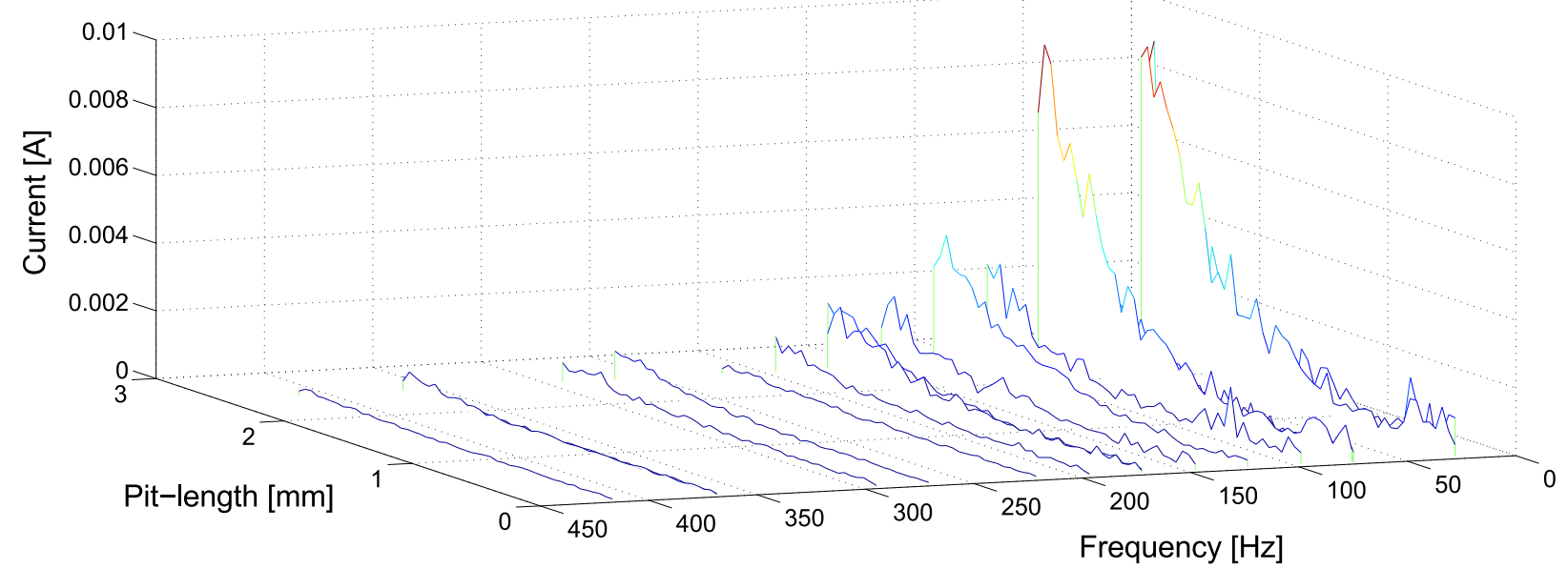

Figure 9: Varying frequency components during the emulation of evolving single point outer race bearing pitting.

accessible rotor-exciter, a platform is created to investigate the relation between the severity of bearing-faults and their reflection in the stator current with high reproducibility. First experiments where conducted and the first results where presented in this paper regarding outer race bearing faults. More specifically, the relation between the pit-length of a single point outer race bearing fault and its corresponding signatures in the current's spectrum was investigated. It can be concluded that a clear relation can be found, defined by a quadratic function with a correlation of $r^{2}=\sim 0.9$, between the magnitude of the fault-indicating current-components and the pit-length. Nevertheless, future research and emulation is needed with other types of bearing faults in order to clearly elucidate the signatures of the different types bearing faults. However, by fitting the trend in the current fault-components by a quadratic curve, an estimation about the severity of the bearing fault can be defined based on the stator current fault components.

\section{REFERENCES}

[1] G. B. Kliman, W. J. Premerlani, B. Yazici, R. a. Koegl, and J. Mazereeuw, "Sensorless, online motor diagnostics," IEEE Computer Applications in Power, vol. 10, no. April, pp. 39-43, 1997.
[2] W. T. Thomson and M. Fenger, "Current signature analysis to detect induction motor faults," IEEE Industry Applications Magazine, vol. 7, no. August, pp. 26-34, 2001.

[3] R. R. Schoen, T. G. Habetler, F. Kamran, and R. G. Bartheld, "Motor bearing damage detection using stator current monitoring," IEEE Transactions on Industry Applications, vol. 31, no. 6, pp. 1274-1279, 1995.

[4] L. Eren and M. J. Devaney, "Bearing Damage Detection via Wavelet Packet Decomposition of the Stator Current," IEEE Transactions on Instrumentation and Measurement, vol. 53, no. 2, pp. 431-436, 2004.

[5] M. Delgado, G. Cirrincione, a. Garcia, J. a. Ortega, and H. Henao, "A novel condition monitoring scheme for bearing faults based on Curvilinear Component Analysis and hierarchical neural networks," Proceedings - 2012 20th International Conference on Electrical Machines, ICEM 2012, pp. 2472-2478, 2012.

[6] W. Saadaoui and K. Jelassi, "Induction motor bearing damage detection using stator current analysis," 2011 International Conference on Power Engineering, Energy and Electrical Drives, no. May, pp. 1-6, 2011.

[7] W. Z. W. Zhou, B. L. B. Lu, T. Habetler, and R. Harley, "Incipient Bearing Fault Detection via Motor Stator Current Noise Cancellation Using Wiener Filter," IEEE Transactions on Industry Applications, vol. 45, no. 4, pp. 1309-1317, 2009.

[8] M. J. Devaney and L. Eren, "Detecting motor bearing faults: Monitoring an induction motor's current and detecting bearing failure," IEEE Instrumentation and Measurement Magazine, vol. 7, no. December 2004, pp. 30-50, 2004

[9] L. Frosini and E. Bassi, "Stator current and motor efficiency as indicators for different types of bearing faults in induction motors," IEEE Transactions on Industrial Electronics, vol. 57, no. 1, pp. 244-251, jan 2010. 
[10] B. Corne, C. Debruyne, P. De Baets, and J. Desmet, "Stator curren measurements as a condition monitoring technology - The-state-of-theart," in 2014 International Conference on Electrical Machines (ICEM). Ieee, sep 2014, pp. 1659-1665.

[11] G. M. Joksimovic and J. Penman, "The detection of inter-turn short circuits in the stator windings of operating motors," IEEE Transactions on Industrial Electronics, vol. 47, no. 5, pp. 1078-1084, 2000.

[12] B. Corne, B. Vervisch, C. Debruyne, J. Knockaert, and J. Desmet, "Comparing MCSA with Vibration Analysis in order to detect Bearing Faults - A Case Study,” pp. 1366-1372, 2015.

[13] B. Corne, J. Knockaert, and J. Desmet, "Emulating Bearing Faults A Novel Approach," International Conference on Electrical Machines 2016, p. 7, 2016

[14] F. Immovilli, C. Bianchini, M. Cocconcelli, A. Bellini, and R. Rubini, "Bearing fault model for induction motor with externally induced vibration," IEEE Transactions on Industrial Electronics, vol. 60, no. 8, pp. 3408-3418, Aug 2013.

[15] A. Brandt, Noise and Vibration Analysis: Signal Analysis and Experimental Procedures. John Wiley and Sons, Ltd, 2011.

[16] G. Schweitzer and E. H. Maslen, Magnetic Bearings. Springer Science and Business Media, 2009.

[17] J. Hillyard, Magnetic Bearings, Joint Advanced Student School. Technical University of Munich, 2006, no. April.

[18] M. Ahrens and L. Kucera, "Analytical calculation of fields, forces and losses of a radial magnetic bearing with a rotating rotor considering eddy currents," 5th Internat. Symp. on Magnetic Bearings, 1996.

[19] K. Radman, N. Bulić, and W. Gruber, "Geometry Optimization of a Bearingless Flux- Switching Slice Motor,” pp. 1695-1701, 2015.

[20] T. Wang and J. Huang, "Radial Position Detection of Five-Phase Bearingless PM Motor," pp. 2604-2610, 2016.

[21] S. McInerny and Y. Dai, "Basic vibration signal processing for bearing fault detection," Education, IEEE Transactions on, vol. 46, no. 1, pp. 149-156, 2003.

[22] B. Yazici and G. B. Kliman, "An adaptive statistical time-frequency method for detection of broken bars and bearing faults in motors using stator current," IEEE Transactions on Industry Applications, vol. 35, no. 2, pp. 442-452, 1999.

[23] J. R. Stack, T. G. Habetler, and R. G. Harley, "Bearing fault detection via autoregressive stator current modeling," IEEE Transactions on Industry Applications, vol. 40, no. 3, pp. 740-746, may 2004

[24] J. R. Stack, T. G. Habeter, and R. G. Harley, "Fault classification and fault signature production for rolling element bearings in electric machines," IEEE Transactions on Industry Applications, vol. 40, no. 3 , pp. 735-739, 2004.

[25] a.M. Knight and S. Bertani, "Mechanical Fault Detection in a MediumSized Induction Motor Using Stator Current Monitoring," IEEE Trans actions on Energy Conversion, vol. 20, no. 4, pp. 753-760, dec 2005.

[26] M. Blodt, P. Granjon, B. Raison, and G. Rostaing, "Models for bearing damage detection in induction motors using stator current monitoring,", IEEE Transactions on Industrial Electronics, vol. 55, no. 4, pp. 1813 $1822,2008$.

\section{BIOGRAPHIES}

Bram Corne received his Master degree in Electrotechnical Engineering from the Technical University HoWest, Kortrijk, Belgium, in 2012. Since 2014, he is a Ph.D. student at Ghent University, Ghent, Belgium, where he is exploring the possibilities of a condition monitoring system based on stator current analysis for driven induction machines.

Bram Vervisch received his master's degree in electrical engineering from the Technical University College of West-Flanders, Kortrijk, Belgium in 2008. He received the $\mathrm{PhD}$ degree from Ghent University, Ghent, Belgium in 2016. Now he is a postdoctoral assistant at the same university continuing his research on mechanical vibrations and machinery fault analysis.

Stijn Derammelaere received the master's degree in automation from the Technical University College of West-Flanders, Kortrijk, Belgium, in 2006. He received the Ph.D. degree from Ghent University, Ghent, Belgium, in 2013 , where he has continued his research concerning control engineering focused on the motion control of fractional horsepower machines.

Jos Knockaert received the degree of industrial engineer in Electrotechnics in 1996 from the University College of Bruges-Ostend, the M.Sc. degree in Electronic System Design in 2001 from Leeds Metropolitan University and the Ph.D. degree in Engineering Science in 2009 from the K.U. Leuven. He worked as EMC-design engineer in the industry and became assistant at the University College of Bruges-Ostend. Since 2010, he is assistant professor at Ghent University, teaching electrical machines, Electromagnetic Compatibility and power electronics.

Sérgio M. A. Cruz was born in Coimbra, Portugal, in 1971. He received the E.E. diploma, and the M.Sc. and Dr. Eng. degrees in electrical engineering from the University of Coimbra, Coimbra, Portugal, in 1994, 1999, and 2004, respectively. Since 1994, he has been with the Department of Electrical and Computer Engineering, University of Coimbra, where he is currently an Assistant Professor and the Director of the Electric Machines Laboratory. He is the author of more than 80 journal and conference papers in his areas of interests. His research interests include electric machines, electric drives, and power electronic converters, with special emphasis on fault diagnosis, fault tolerance, and digital control.

Jan J. M. Desmet received the Polytechnical Engineer degree from the polytechnic academy in Kortrijk, the M.Sc. degree in Electrical Engineering from the V.U.Brussels and in his Ph.D. degree at the K.U.Leuven, Belgium. Currently he is full professor at the Ghent University teaching power quality, renewables and industrial electric measurement techniques. Besides his job as full professor and researcher, he also is member of several expert colleges, IEEE senior member, member of SC77A (IEC), TC210 (CENELEC), member of the CIRED Technical Committee TC2 and in the CIGRE JWG C4.24. Since November 2014, research group Lemcko became member of the DERLab group. 